\title{
The Effect of Fluoroethylene Carbonate as an Additive on the Solid Electrolyte Interphase on Silicon Lithium-Ion Electrodes
}

\author{
Kjell Schroder, ${ }^{\dagger, \mathbb{I}}$ Judith Alvarado, ${ }^{\ddagger}, \mathbb{I}$ Thomas A. Yersak, ${ }^{\ddagger}, \perp$ Juchuan Li, ${ }^{\S}$ Nancy Dudney, ${ }^{\S}$ \\ Lauren J. Webb, ${ }^{*}{ }^{\dagger}$ Ying Shirley Meng, ${ }^{*}+\frac{\hbar}{*}$ and Keith J. Stevenson*, ${ }^{\dagger}$ \\ ${ }^{\dagger}$ Materials Science and Engineering Program, Texas Materials Institute, and Department of Chemistry, University of Texas at Austin, \\ Austin, Texas 78712, United States \\ ${ }^{\ddagger}$ Department of NanoEngineering, University of California San Diego, La Jolla, California 92093, United States \\ ${ }^{\S}$ Materials Science and Technology Division, Oak Ridge National Laboratory, One Bethel Valley Road, Oak Ridge, Tennessee 37830, \\ United States
}

Supporting Information

ABSTRACT: Fluoroethylene carbonate (FEC) has become a standard electrolyte additive for use with silicon negative electrodes, but how FEC affects solid electrolyte interphase (SEI) formation on the silicon anode's surface is still not well understood. Herein, SEI formed from $\mathrm{LiPF}_{6}$-based carbonate electrolytes, with and without FEC, were investigated on $50 \mathrm{~nm}$ thick amorphous silicon thin film electrodes to understand the role of FEC on silicon electrode surface reactions. In contrast to previous work, anhydrous and anoxic techniques were used to prevent air and moisture contamination of prepared SEI films. This allowed for accurate characterization of the SEI structure and composition by X-ray photoelectron

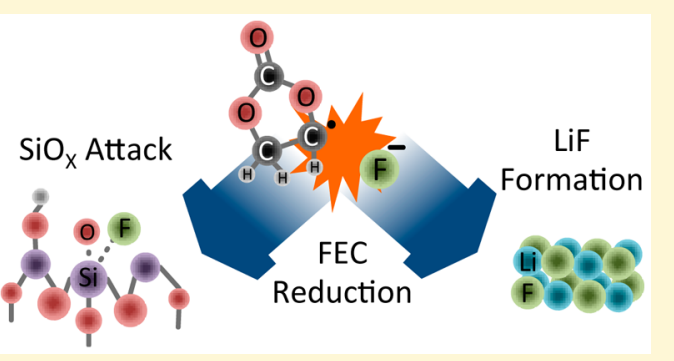
spectroscopy and time-of-flight secondary ion mass spectrometry depth profiling. These results show that FEC reduction leads to fluoride ion and $\mathrm{LiF}$ formation, consistent with previous computational and experimental results. Surprisingly, we also find that these species decrease lithium-ion solubility and increase the reactivity of the silicon surface. We conclude that the effectiveness of FEC at improving the Coulombic efficiency and capacity retention is due to fluoride ion formation from reduction of the electrolyte, which leads to the chemical attack of any silicon-oxide surface passivation layers and the formation of a kinetically stable SEI comprising predominately lithium fluoride and lithium oxide.

\section{INTRODUCTION}

Silicon-lithium alloys have been the subject of intense research as a negative electrode active material in lithium-ion batteries (LIBs). The high theoretical gravimetric capacity of lithiated silicon has motivated this research; however, major challenges remain for the implementation of silicon in commercial devices. Upon lithiation, silicon undergoes a volume expansion of about $300 \%$. This causes mechanical breakdown and loss of electrical connection between the active material and the current collector, in turn causing lost capacity and electrode inactivity. ${ }^{1,2}$ By using nanostructured electrodes, the mechanical pulverization of the $\mathrm{Si}$ active material has largely been mitigated. $^{3-7}$ For example, Si nanoparticles with a diameter less than $\sim 150 \mathrm{~nm}$ can accommodate the strain of full lithiation without fracturing. ${ }^{1,8-11}$ Additionally, a wide range of electronically conductive binders and electrode coatings have been developed to address the pulverization of the overall composite electrode structure. ${ }^{12,13}$ Unfortunately, nanostructures and complicated architectures generally lead to low tap (volumetric) density electrodes with extremely high surface areas. Such high surface area electrodes exacerbate capacity losses (and diminish electrode cycle life) through parasitic surface reactions. ${ }^{14}$ Moreover, in a composite electrode, the conductive additive and binder also participate in surface reactions, which make it difficult to isolate the effects of each electrode component on particular surface chemistries. ${ }^{15}$

Because interfacial chemistry on next generation negative electrode materials like silicon is not well understood, rational design and control of new battery architectures is not possible. ${ }^{11,16}$ The traditional electrolyte, $\mathrm{LiPF}_{6}$ salt in diethyl carbonate (DEC) and ethylene carbonate (EC), 1:1 by \% wt., is unstable at normal battery cycling potentials (lithiation and delithiation below $1.0 \mathrm{~V}$ versus $\mathrm{Li} / \mathrm{Li}^{+}$). During the lithiation process, a portion of the $\mathrm{Li}$ ions is consumed as the electrolyte is reduced to inactive side products in parasitic reactions. Some of these parasitic reactions form insoluble products that result in a solid electrolyte interphase (SEI), which coats the negative electrode's surface. ${ }^{17-19}$ The SEI components are generally electronically insulating in nature and passivate (to some degree) the active material's surface from further solvent reduction. As a result, the SEI hinders further progression of the parasitic reactions to minimize the capacity loss due to

Received: May 1, 2015

Revised: July 6, 2015

Published: August 3, 2015 
irreversible sequestration of lithium ions. Therefore, SEI stability directly relates to the loss of capacity in LIBs. Incomplete passivation of the electrode surface truncates the battery cycle life because of the continued consumption of lithium throughout electrochemical cycling. ${ }^{20-22}$

For silicon, one of the more successful strategies for dealing with the capacity loss associated with electrochemical cycling and continuous electrolyte decomposition has been the use of battery electrolyte additives such as cosolvents and cosalts. Of these, fluoroethylene carbonate (FEC) has been very successful at extending battery cycle life. Its unique performance has made it a standard additive in the literature for almost all silicon electrodes. ${ }^{23-26}$ As discussed earlier, cycle life is linked to SEI stability; however, the connection between SEI stability and FEC is still not well understood. Calculations by Balbuena and co-workers have suggested that the kinetically fast reduction of FEC to neutral radical carbonate and fluoride anion leads to rapid formation of $\mathrm{LiF}$ in the $\mathrm{SEI}^{27-29}$ On the other hand, previous work has proposed that polycarbonates such as polymeric fluorocarbonate and polymeric vinylene carbonate are formed during the reduction of FEC and play a role in stabilizing the SEI or promoting Li-ion transport during electrochemical cycling. ${ }^{23,24,30,31}$

To understand how the inclusion of FEC in the electrolyte affects SEI structure and its evolution, we attempt to reconcile the differing accounts by (1) using mechanically stable amorphous $\mathrm{Si}(a-\mathrm{Si})$ thin film electrodes as a model system and (2) extending previously developed anoxic and anhydrous analytical characterization techniques of silicon electrodes.

As shown by Lucht et al. as well as Abraham et al., model systems free of binder and conductive additives are important for understanding the chemical composition of the SEI. ${ }^{32-35} \mathrm{Li}$ and co-workers have shown that direct current (DC)-sputtered $a$-Si thin film electrodes with a film thickness below the critical dimension of $150 \mathrm{~nm}$ or less are mechanically stable during their formative cycles. ${ }^{36}$ To limit the irreversibility due to mechanical pulverization, we use a model system of binder-free and conductive additive-free $50 \mathrm{~nm}$ thick DC-sputtered $a$-Si thin films on copper foil. Unlike crystalline silicon, $a-S i$ experiences much less strain and mechanical deterioration with cycling because of reduced lattice mismatch associated with the sharp two-phase silicon lithiation mechanism. ${ }^{37,38}$ By using a stable model system, we can better relate the addition of FEC cosolvent directly with the electrochemical results and surface properties such as SEI stability, structure, and chemical makeup.

To accurately characterize and understand how the inclusion of FEC in the electrolyte affects SEI structure and evolution, we extend previously developed anoxic and anhydrous X-ray photoelectron spectroscopy (XPS) ${ }^{39-41}$ and time-of-flight secondary ion mass spectrometry (TOF-SIMS) ${ }^{40,42}$ measurement techniques to our model system. In much of the previous experimental work on SEI formed from electrolytes with FEC, ${ }^{23,24,30,35}$ there was no discussion of the known effects of exposing SEI to ambient conditions. ${ }^{39,41}$ However, Xu et al. ${ }^{43}$ have used a special-built airtight transfer system to avoid air exposure during sample analysis. Although similar sample preparation precautions were taken in our study, $\mathrm{Xu}$ et al. used nanoparticle composite electrodes. As previously mentioned, it is widely accepted that both the conductive additive and binder contribute to the SEI formation; therefore, it is difficult to solely isolate the decomposition products formed from the electrolyte. Ultimately, their findings suggest that FEC containing electrolyte preserves electrode integrity by prevent- ing particle agglomeration, cracking, and influencing the salt dissolution reaction. Building on this work and others, we discuss the differences between the electrode cycled in EC/ DEC versus EC/DEC/FEC using a model system. Characterization by XPS and TOF-SIMS depth profiling elucidates the reaction pathways that lead to thicker $\mathrm{SEI}$, increased $\mathrm{LiF}$ formation, $\mathrm{Li}_{2} \mathrm{O}$ formation, and increased silicon surface reactivity.

\section{METHODS}

Fifty nanometer $a$-Si thin film substrates were fabricated by DC sputtering. Thin films sputtered onto rough copper foil were repeatedly lithiated and delithiated (cycled) to understand the structure of the SEI resulting from electrolyte containing FEC. The electrodes where then analyzed by TOF-SIMS and XPS by closely following methods described previously for anoxic and anhydrous characterization with minimal exposure to oxygen and water. ${ }^{39,40}$

Silicon Materials. Amorphous silicon thin films $(50 \mathrm{~nm})$ were fabricated by DC sputtering from an undoped Si target (99.999\%) and deposited on battery grade copper foil. To calibrate the TOF-SIMS depth profiling experiments, $a$-Si $50 \mathrm{~nm}$ films were sputtered on $\mathrm{Si}$ wafers. For these samples, a metallic layer of $200 \mathrm{~nm} \mathrm{Cu}$ (99.999\%) and $200 \mathrm{~nm} \mathrm{Ti} \mathrm{(99.995 \% )} \mathrm{was} \mathrm{deposited} \mathrm{on} \mathrm{Si} \mathrm{wafer} \mathrm{as} \mathrm{the} \mathrm{current}$ collector followed by $50 \mathrm{~nm}$ a-Si film. All sputtering was carried out under pure argon atmosphere (99.9995\%). A quartz crystal microbalance was used to monitor the film thickness. The films were exposed to air prior to battery assembly.

Electrochemistry. The $a$-Si thin films were assembled into 2032 coin cells using a Celgard (C480) polyprolylene separator (Celgard Inc., USA), $1 \mathrm{M} \mathrm{LiPF}$ (electrolyte solutions (battery grade, BASF) including traditional 1:1 (wt \%) EC:DEC, (hereafter "EC/DEC") and a blend of 45:45:10 (wt \%) EC/DEC/FEC, (hereafter "EC/DEC/ FEC"), with lithium metal as the counter electrode. The electrochemical cells were assembled in a glovebox purged with high purity argon (99.9995\%) and maintained with oxygen and water vapor levels at or less than $5 \mathrm{ppm}$. After assembly, the electrochemical properties of the two-electrode cells were measured on an Arbin battery cycler in galvanostatic mode. The open-circuit voltage of the coin cells was monitored for $1.5 \mathrm{~h}$, and then the cells were charged and discharged between 2.0 and $0.05 \mathrm{~V}$, with a current density of $21 \mu \mathrm{A} / \mathrm{cm}^{2}$, which is approximately $\mathrm{C} / 2$ rate at room temperature. Additionally, electrochemical impedance spectroscopy (EIS) measurements were carried out with $\mathrm{AC}$ frequencies from 0.01 to $1 \times 10^{6} \mathrm{~Hz}$ on galvanostatic cycled $a$-Si electrodes in lithiated and delithiated states, as described earlier. In a classical three-electrode cell, the voltage can be applied and measured between the working and reference electrode, and current is collected on the counter electrode. However, in this study, the impendence was collected in a half cell (pseudo three-electrode cell) using a Solatron 1287 Potentiostat after first lithiation, first delithiation, and 100 cycles delithiation. After the EIS measurements were taken, an equivalent circuit model was fit to the data to analyze the reactions that took place using $\mathrm{Z}$ view software (v. 3.4a, Scribner Associates, Inc.).

Surface Analysis. After electrochemical cycling, the cells were disassembled in the glovebox, then transferred to the ultrahigh-vacuum environment using a reduced oxidation $(\mathrm{ROx})$ interface designed for transferring air-sensitive samples. The ROx has methods and figures of merit to determine if the samples are ever exposed to additional traces of oxygen and water greater than those experienced in the glovebox environment, even during pump-down. The methods and components of the $\mathrm{ROx}$ are described in further detail in the Supporting Information and elsewhere. ${ }^{39,40,44}$

XPS was performed using a Kratos Ultra DLD XPS. Analysis of the spectra closely followed previous work, with fitting performed by CasaXPS software (version 2.3.15, Casa Software Ltd.); ${ }^{39,40}$ an example fit is given in the Supporting Information (Figure S2).

TOF-SIMS data were collected using an ION-TOF GmbH TOF.SIMS 5, again closely following previous work. ${ }^{40}$ TOF-SIMS depth profiling experiments were performed by a dual ion beam 
interrogation of the surface, alternating between an analysis beam (primary) $\left(\mathrm{Bi}_{3}{ }^{2+}\right.$ ions) and sputtering beam (secondary) $\left(\mathrm{Cs}^{+}\right.$ions). Full spectra from 1-1000 amu were acquired in negative ion mode at pressures between $5 \times 10^{-8}$ and $9 \times 10^{-9} \mathrm{mbar}$, with mass resolution better than $8000(\mathrm{~m} / \Delta \mathrm{m})$.

TOF-SIMS spectra were analyzed with the ION-TOF software package (version 6.3). Mass calibration used a set of only inorganic peaks. ${ }^{45}$ After depth profiling, samples were removed from the TOFSIMS, and sputtering craters were analyzed by optical profilometry (Veeco, NT9100 Optical Profiler). Additional samples for calibration were fabricated by DC sputtering $a$-Si thin films on metalized silicon wafer (discussed in more detail in the Supporting Information). Sputtering times and crater depths were used to determine sputtering rates for both the SEI layer and the wafer by a linear fit of the sputtering depth versus sputtering time data. The resulting sputtering rates were used to transform sputtering time into depth using a simple two-layer sputtering model. ${ }^{40,46,47}$ A homemade script executed in the iPython nootbook interpreter environment using the numpy, scipy, and pandas libraries organized and transformed the data from the time domain to depth. ${ }^{48-51}$ The $\mathrm{Si}^{-}$mass fragment signal was used to define the relative contributions of each sputtering rate in the transition between the SEI and the silicon active material. The outer surface of the silicon active material was defined to be where $\mathrm{Si}^{-}$ intensity was halfway between its maximum and minimum signal values.

\section{RESULTS AND DISCUSSION}

Galvanostatic Cycling of $a$-Si Thin Film Electrodes. To understand the effects of FEC, SEI formed from the EC/DEC and EC/DEC/FEC electrolyte systems were compared. To form the SEI, thin film electrodes underwent controlled lithiation (discharge) and delithation (charge) by constant applied current while measuring the voltage, as described earlier. Figure 1 shows representative charge/discharge curves for three particular cycles taken from electrodes that were cycled 100 times. The applied current drove lithium-silicon alloy formation as well as decomposition of the electrolyte via parasitic reactions, some of which resulted in the formation of the SEI. It is common practice to plot the charge applied to the system in terms of the mass of active material ("capacity"), where one can observe how much of the active material is used during electrochemical cycling. However, it is important to note that some charge is consumed during the formation of the parasitic side reactions, which should not be interpreted as used active material.

In addition to using the integrated current applied during cycling to determine capacity, the mass loading of silicon deposited on the copper foil was also used. By using the mass loading per half-inch electrode $\left(11.65 \mu \mathrm{g} \mathrm{cm}^{-2}\right)$, the capacity for the lithiated thin film cycled with the EC/DEC was calculated to be $4446.2 \mathrm{mAh} \mathrm{g}^{-1}$, and the electrode cycled with EC/DEC/FEC electrolyte was calculated to be $4525.84 \mathrm{mAh}$ $\mathrm{g}^{-1}$.

The voltage profiles include two curves: the left-most solid and dashed curves indicate the lithiation of the material, and the right-most indicate the delithation of the material. Regions in the voltage profiles where capacity changed more rapidly than the voltage are defined as voltage plateaus. These plateaus are also observed as peaks in differential capacity plots, also known as $\mathrm{dQdV}^{-1}$ plots or pseudocyclic voltammograms, shown in the Supporting Information (Figure S1). In the first lithiation (Figure 1a), plots resulting from both electrodes have a small plateau at $0.42 \mathrm{~V}$ versus $\mathrm{Li} / \mathrm{Li}^{+}$. This plateau diminishes to the point of being unobservable by the tenth cycle (Figure 1b). On the basis of the potential at which this reaction takes

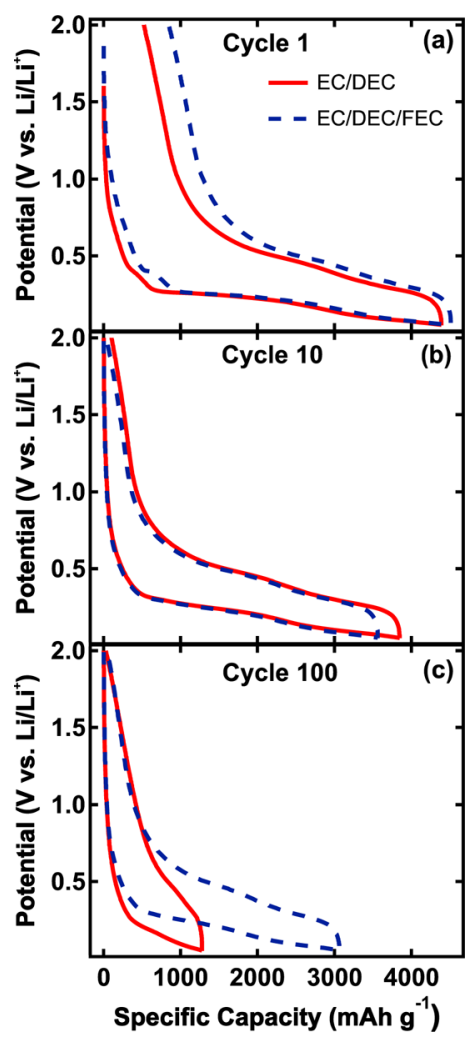

Figure 1. Voltage profiles of half cells taken during the (a) first cycle, (b) tenth cycle, and (c) one-hundredth cycle. Cells were cycled with $\mathrm{EC} / \mathrm{DEC}$ (solid red line) and EC/DEC/FEC (dashed navy line) electrolytes.

place and previous work, we attribute this behavior to the reduction/lithiation of native oxide layer on the electrodes. ${ }^{52-55}$

Lithiation and delithation reactions that took place during the first cycle for both electrodes (Figure 1a) are shown in the plateaus at 0.262 and $0.076 \mathrm{~V}$ during reduction and at 0.285 and $0.488 \mathrm{~V}$ during oxidation. There is a slight decrease in the potential of the first lithiation reaction between the first and hundredth cycles (Figure 1c) for both electrodes cycled in both electrolytes. However, the shift to less positive potential for lithiation and more positive potential for delithation is greater for the electrode cycled in EC/DEC, which indicates an increase in overpotential with continued cycling. We attribute this behavior to increased resistance to ionic transport in the SEI for reasons discussed in more detail in the following. Conversely, the lithiation plateaus hardly shift between the tenth and hundredth cycles for the electrode cycled in EC/ DEC/FEC.

More qualitatively, the plateaus for the electrode cycled in EC/DEC (solid red line) deform from Figure 1, panel a to panel c. The profile changes to poorly defined potentials at 100 cycles in Figure 1, panel c. The electrode cycled in EC/DEC/ FEC (dashed navy line) displayed similar behavior in the first cycle (Figure 1a), and hardly any change is observed between the tenth and hundredth cycles (Figures $1 b, c)$. This indicates that the free energy required to lithiate is more poorly defined after 100 cycles for the electrode cycled in EC/DEC relative to the electrode cycled in EC/DEC/FEC. This could be due to the transport properties of each respective SEI or a degradation in the active material caused by repeated cycling (i.e., no clear phase equilibrium between lithiated and delithiated silicon). 
Figure 2 shows the evolution of the specific capacity and Columbic efficiency for electrodes cycled in each electrolyte
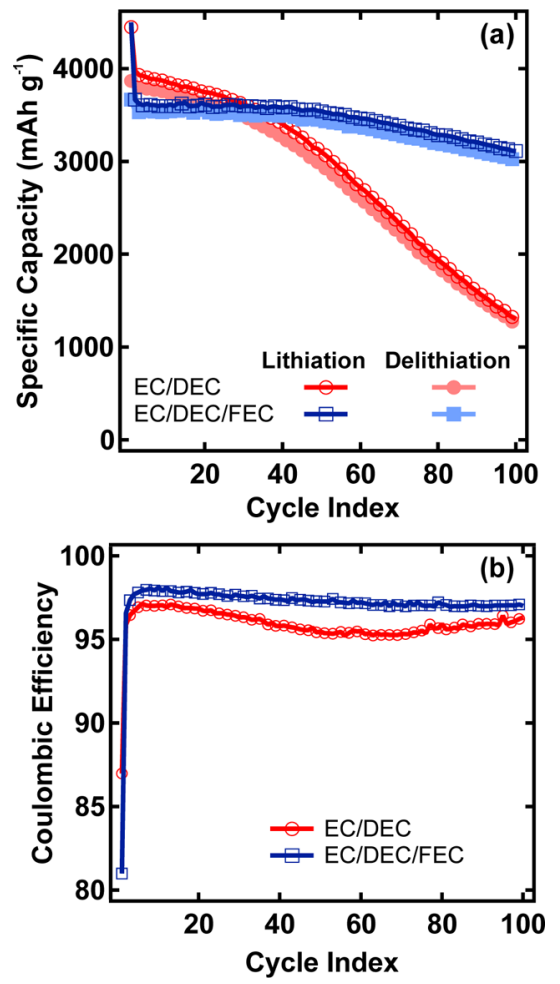

Figure 2. (a) Specific capacity versus cycle at $\sim \mathrm{C} / 2$ rate and (b) Coulombic efficiency as a function of cycle for $a$-Si thin film electrodes galvanostatically charged and discharges in EC/DEC (red circles) and $\mathrm{EC} / \mathrm{DEC} / \mathrm{FEC}$ (navy squares).

system described earlier. As previously mentioned, by noting the $x$-axis value obtained at the end of each half cycle, an empirical estimate of the storage capacity of the $a$-Si thin film electrodes can be found. This capacity is shown for each half cycle in Figure 2, panel a. The ratio of the two capacity values is the Coulombic efficiency (CE), a measure of the irreversibility of the reactions that participate in each cycle, shown in Figure 2, panel b.

In Figure 2, panel a, we note that the electrode cycled with EC/DEC exhibited higher capacity up to the 37th cycle compared to the electrode cycled in EC/DEC/FEC. However, with the exception of the first cycle, the electrode cycled with EC/DEC/FEC had superior capacity retention and CE (Figure 2b) compared to the electrode cycled with EC/DEC. The electrode cycled in EC/DEC continued to lose capacity in each cycle until 100 cycles were reached, while the electrode in EC/ DEC/FEC maintained its capacity for the first 40 cycles and then decreased gradually thereafter.

The electrodes were not precycled in any way; therefore, the information from the first cycle reports on the formation of the SEI in both of the electrolytes used. After the first delithiation, the electrode cycled in EC/DEC had a capacity of 3867.3 $\mathrm{mAhg}^{-1}$, while the electrode cycled in EC/DEC/FEC had a capacity of $3665.21 \mathrm{mAhg}^{-1}$. Upon delithiation, neither electrode returned to 0.0 capacity (Figure 1a) at the nominal open circuit voltage of $2.0 \mathrm{~V}$. This was due to electrons measured during reduction and lithiation that were not recovered upon oxidation and delithiation. As a result, in the first cycle, the electrode cycled in EC/DEC had a CE of
$86.95 \%$, and the electrode cycled in EC/DEC/FEC had a CE of $80.96 \%$ (Figure 2b).

After the tenth lithiation (Figures $1 \mathrm{~b}$ and $2 \mathrm{a}$ ), despite having a lower initial theoretical capacity, the electrode cycled with EC/DEC showed higher capacity $\left(3858.5 \mathrm{mAhg}^{-1}\right)$ compared to the electrode cycled in EC/DEC/FEC (3597.2 $\left.\mathrm{mAhg}^{-1}\right)$. However, even though the capacity of the electrode cycled in $\mathrm{EC} / \mathrm{DEC}$ was higher, its $\mathrm{CE}$ was lower compared to that of the electrode cycled in EC/DEC/FEC (Figure 2b).

By the 100th cycle (Figure 1c), the electrode cycled in EC/ DEC/FEC maintained a capacity above $3000 \mathrm{mAhg}^{-1}$, while the electrode cycled in EC/DEC suffered from severe capacity fade (down to $1252 \mathrm{mAhg}^{-1}$ ). The relative performance of the two electrolytes is in good agreement with the previous results shown in the literature, where the addition of FEC to the electrolyte improves capacity retention and $\mathrm{CE}$ over prolonged cycles. $^{23-26,35}$

We attribute the observed difference in loss of capacity between the electrodes to surface processes and not mechanical degradation. We can deduce that changes in capacity are due to surface properties because of the mechanical stability of both thin-film electrodes, which do not show delamination or mechanical failure (see Supporting Information, Figure S4). As a result, discrepancies in the amount of $\mathrm{CE}$ decrease experienced by the electrodes must come from (1) continued progression of electrochemical parasitic reactions and incomplete surface passivation of the $a$-Si electrodes by the SEI or (2) lithium retained in the active material, for example, as a reduced silicon-lithium oxide $\left(\mathrm{Li}_{x} \mathrm{SiO}_{y}\right){ }^{52-56}$

Before we look at the electrochemical evidence for differences in the SEI formation and stability in the electrode/electrolyte systems, we will consider what is already known about EC/DEC/FEC blends in comparison to EC/ DEC. Previous work suggested that the chemical composition and evolution of the SEI are controlled by the reaction kinetics of (1) the initial reactants, such as the electrolyte and additives, and (2) the initial, insoluble, parasitic reaction products. $^{15,17,57,58}$ According to Balbuena and co-workers, density functional theory (DFT) calculations predict that FEC selectively decomposes over DEC and EC by a comparatively high rate. The reduction mechanism follows a one electron lithium-assisted reduction of the fluoromethyl group to fluoride and neutral radical carbonate to form $\mathrm{LiF}$ as a main reduction product. $^{27-29}$ Scheme 1 shows reactions that produce LiF and either ethylene and carbonate as products (reaction 1) or alternately alkoxy products (reaction 2). Nie, Abramham, and

Scheme 1. Reaction 1, Electroreduction of Fluoroethylene Carbonate To Form Lithium Fluoride, Lithium Carbonate, and Ethylene; Reaction 2, Electroreduction of Fluoroethylene Carbonate To Form Lithium Fluoride, Methylenedioxyl Ion (or Alternately Carbon Dioxide), and Lithium Ethoxide

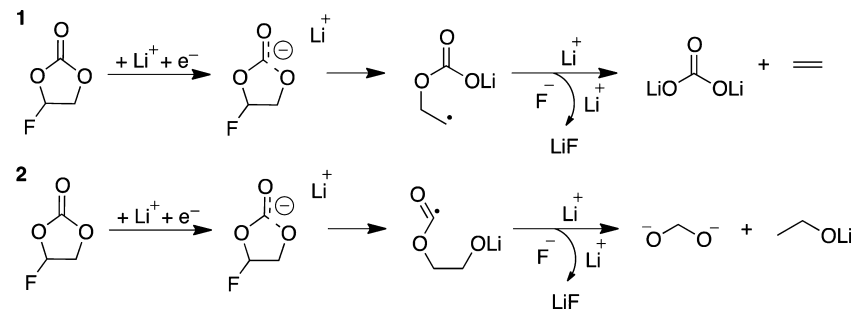


Lucht et al. have also established the prominence of LiF in SEI derived from FEC reduction compared to other carbonate solvents. ${ }^{35}$

In the first cycle, we observe that $\mathrm{EC} / \mathrm{DEC} / \mathrm{FEC}$ has worse $\mathrm{CE}$ than EC/DEC (Figure 2b). If more charge and lithium are consumed in the first cycle when the electrode is cycled in EC/ $\mathrm{DEC} / \mathrm{FEC}$ versus an electrode cycled in EC/DEC, then this suggests that the reduction rate is greater for FEC than EC. ${ }^{43}$ Therefore, the addition of FEC to the electrolyte generates a large amount of $\mathrm{LiF}$ in the first cycle. This further suggests that the reduction reactions of all carbonates below $1.0 \mathrm{~V} \mathrm{Li} / \mathrm{Li}^{+}$are in a kinetically limited regime where the rate-limiting step involves the carbonate species reduction and not charge transfer to the solvent. Because we are comparing surfaces of similar area while maintaining mechanical stability, we are able to detect this shift in the SEI formation reactions, which was not observed in previous work.

The direct electrochemistry observations in the first cycle also support the idea that the difference in $\mathrm{CE}$ between the two electrolyte systems is due to SEI formation in the first cycle. We observed a larger increase in "capacity" above $\sim 0.5 \mathrm{~V}$ versus $\mathrm{Li} /$ $\mathrm{Li}^{+}$in the electrode cycled in EC/DEC/FEC during the first cycle (Figure 1a, dashed navy line). Since there are no electrochemical processes related to the lithiation of the electrode at these potentials, the electrode cycled in EC/ DEC/FEC must have consumed more charge during the formation of the SEI prior to the actual lithiation of the electrode.

These results are in contrast to previous literature, where it has been shown that adding FEC to a carbonate based electrolyte improves the initial CE. This result has been observed even on conductive additive and binder-free electrodes such as $a-S i$ thin films, nanowires, and nanoparticles. $^{24,30,31,34}$ Nakai et al. and $\mathrm{Nie}$ et al. both observed roughly equal $\mathrm{CE}$ values between electrodes cycled in EC/ DEC/FEC and EC/DEC electrolytes. However, Nakai et al. used relatively thick, $\sim 2 \mu \mathrm{m}, a$-Si thin film electrodes. The use of such thick electrodes makes it difficult to attribute the difference in $\mathrm{CE}$ to surface reactions and not other factors related to mechanical stability. ${ }^{36}$ It is also difficult to compare electrodes made with nanostructured active material because of the inhomogeneity in surface area of each electrode when made on a laboratory scale. Here, the small change in porosity and particle packing can have a large effect on the SEI and lithiation rate of the active material. ${ }^{14}$ In the present work, we use thin films grown during the same deposition event to obtain a relatively controlled surface area and morphology from electrode to electrode.

Because the electrode cycled in EC/DEC/FEC shows better $\mathrm{CE}$ after the first cycle, we propose that the SEI formed during electrochemical cycling is better at passivating the surface from further reactions. To better understand the mechanisms of SEI formation and how the SEI from the two electrolytes differs, we turn to surface analytical techniques.

Surface Analysis by XPS and TOF-SIMS Depth Profiling. The complex and coupled nature of the parasitic surface reactions makes it difficult to directly observe their products and reduction mechanisms. Here, the structure and chemistry of the SEI are determined by surface analysis via XPS and TOF-SIMS (Figures 4 and 5) post hoc, avoiding environmental contamination by water vapor or oxygen, which can be detrimental to the SEI. By studying the SEI composition on a model system, we gain insights into the reduction mechanism of EC/DEC/FEC from its SEI structure via both XPS and TOF-SIMS depth profiling.

DC sputtered $a-S i$ electrodes with SEI formed in both electrolytes underwent the following galvanostatic experiments: (1) a single lithiation event, (2) one complete lithiation and delithiation cycle, and (3) one-hundred cycles. Each electrode surface was characterized first by XPS analysis, then by dualbeam TOF-SIMS depth profiling.

The XPS assignments (Figure 3) follow a careful selfconsistent fitting model and are similar to previously reported

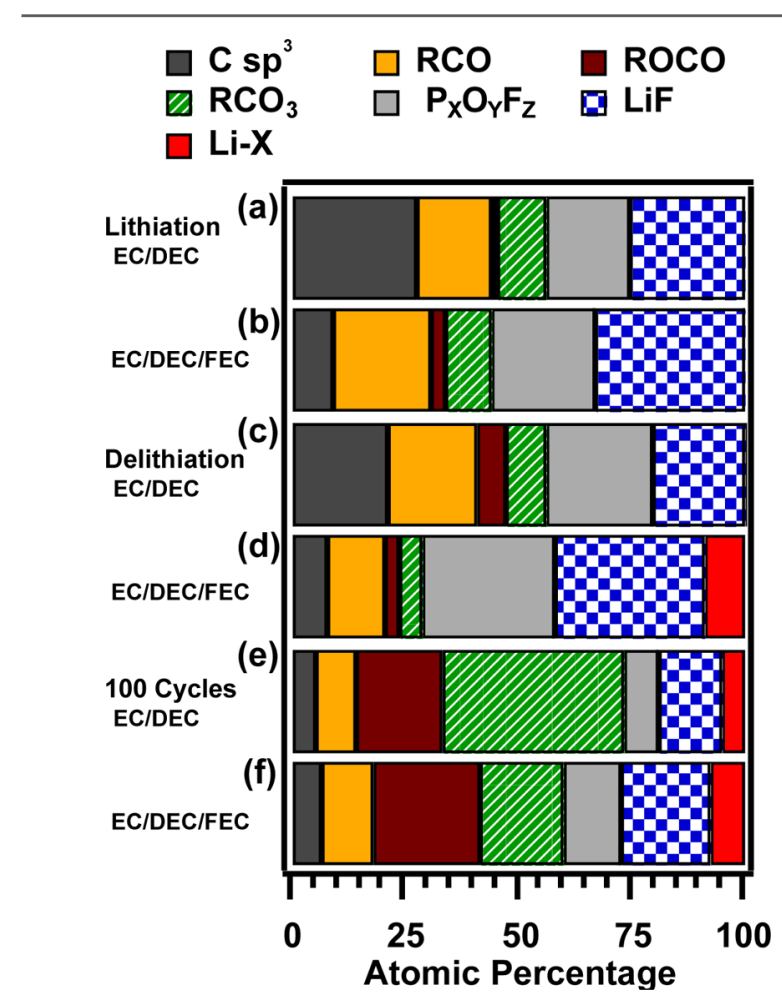

Figure 3. Relative composition of the $10 \mathrm{~nm}$ outer SEI after (a, b) first lithiation, (c, d) first delithiation, and (e, f) 100 cycles in the delithiated state. The layer resulted from and was in fluid communication with EC/DEC (a, c, e) and EC/DEC/FEC (b, d, f).

results for SEI formed on other silicon model systems. ${ }^{39,40}$ The identified chemistries included organics such as aliphatic carbon

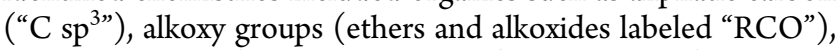
carboxyl groups (carboxylates, esters) or oxalates (all labeled "ROCO"), and carbonic esters or ionic carbonate salts (" $\mathrm{RCO}_{3}$ "). Inorganic functionalities include lithium fluoride ("LiF") and fluoro-phosphoro- oxides (" $\mathrm{P}_{x} \mathrm{O}_{y} \mathrm{~F}_{z}$ "). Lithium signal that could not be attributed to lithium fluoride is labeled "Li-X", which may include alkyl lithium, inorganic lithium oxide, and lithium phosphoro-oxy-fluoride compounds. Additionally, lithium included in the $\mathrm{Li}-\mathrm{X}$ functionalities, as well as oxygen attributed to $\mathrm{P}_{x} \mathrm{O}_{y} \mathrm{~F}_{z}$, may in fact be part of lithiumsilicon oxide $\left(\mathrm{Li}_{x} \mathrm{SiO}_{y}\right)$ following the work of Philippe et al., Martin et al., and Radvanyi and co-workers. ${ }^{52-55} \mathrm{~A}$ small, yet detectable amount of lithium oxide (" $\mathrm{LiO}_{x}$ ") was observed in one experiment and will be discussed in further detail. It can be difficult to distinguish between hydroxide, peroxide, and oxide compounds by XPS; therefore, the $\mathrm{LiO}_{x}$ assignment includes all of these functionalities.

It should be noted that due to the mean-free path of the photoexcited electrons, the compositions measured by XPS are 
only representative of the outermost $\sim 10 \mathrm{~nm}$ film thickness of the SEI.

TOF-SIMS assignments (Figure 4) follow the work by Schroder et al. ${ }^{40}$ and only represent a small subset of marker
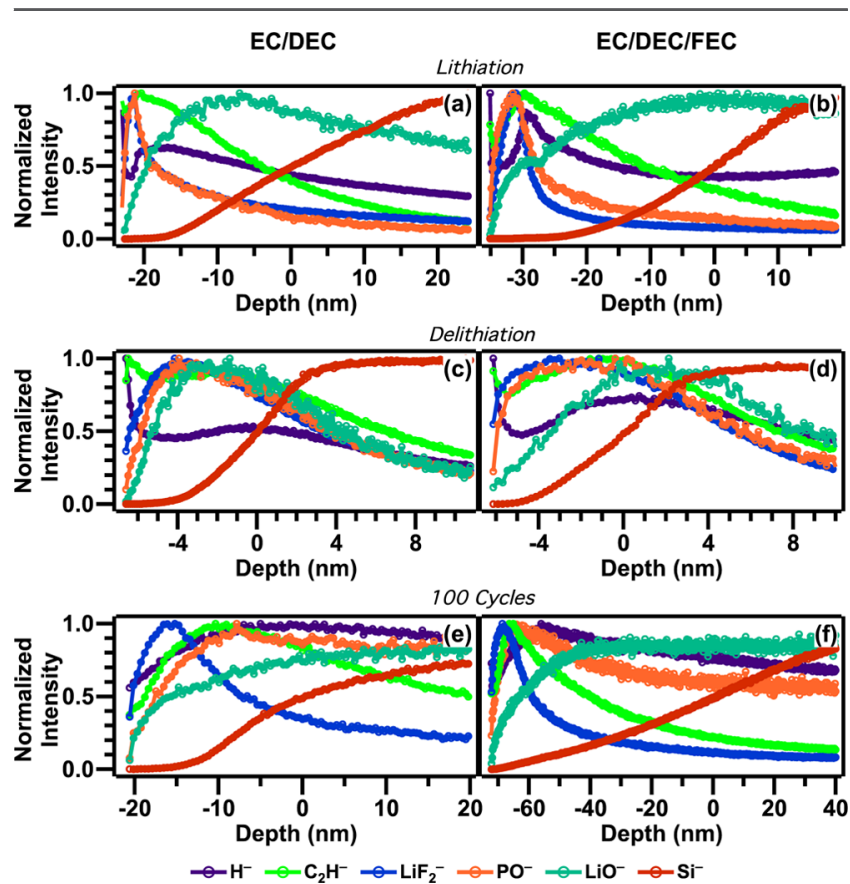

Figure 4. TOF-SIMS depth profiles of SEI resulting from both EC/ DEC (left column) and EC/DEC/FEC (right column) electrolytes that have undergone (a, b) galvanostatic lithiation, $(c, d)$ one full cycle of galvanostatic lithiation and delithation, and (e, f) 100 galvanostatic cycles. It should be noted that each subfigure is plotted on its own $x$ axis; the thickness of each SEI varies significantly as it evolves, and each is on their own scale to better see the changes in the secondary ions' normalized signal. Negative depths are above the surface of the $a$ $\mathrm{Si}$ electrode, and positive depths go below the surface.

species used to identify the layered structure of the SEI. Determining the complete chemistry of the SEI from secondary mass fragments in an inhomogeneous, poorly controlled, mixed inorganic/organic interface is outside the scope of this work. ${ }^{40,42,59}$ In lieu of comparing different functionalities directly (e.g., relative concentrations of organic and inorganic species), the depth profiles consist of the signals of particular secondary ion mass fragments normalized to each fragment's maximum measured intensity. Identifying the maximum intensity allows us to discuss the structure of the SEI in terms of intermixing strata and microphases consistent with the kinetic stability theory of the SEI summarized by Peled and Golodnitsky. ${ }^{17}$ Accordingly, we use the $\mathrm{C}_{2} \mathrm{H}^{-}$mass fragment as a marker for organic species (with $\mathrm{H}^{-}$shown to provide context for the fragmentation of these species). The $\mathrm{PO}^{-}$and $\mathrm{LiF}_{2}{ }^{-}$are markers for the inorganic compounds such as $\mathrm{P}_{x} \mathrm{O}_{y} \mathrm{~F}_{z}$ and $\mathrm{LiF}$ species. $\mathrm{LiO}^{-}$is also present, and we have attributed its source to a mixture of $\mathrm{LiO}_{x}$ species as well as $\mathrm{Li}_{x} \mathrm{SiO}_{y}$ formed during reduction of the native oxide present on the electrodes.

All mass fragments are plotted as a function of depth, with $50 \%$ of the maximum (steady state) $\mathrm{Si}^{-}$fragment signal taken as the surface of the electrode. It should also be noted that the depth profiles are plotted on their own differing $x$-axes to highlight each ion's changing signal with depth. Additionally, when discussing the ion signals it is important to remember that the overlapping intensities are the result of multiple factors, including knock-in, recoil, and interfacial roughness effects. ${ }^{40}$

Comparing the lithiated electrodes (Figures $3 \mathrm{a}, \mathrm{b}$ and $4 \mathrm{a}, \mathrm{b}$ ), we observe changes in the chemical composition and stratification consistent with the calculations done by Balbuena and co-workers. First, from the XPS, the SEI resulting from the $\mathrm{EC} / \mathrm{DEC} / \mathrm{FEC}$ electrolyte had increased concentration of inorganic species (Figure 3b), specifically $\mathrm{LiF}$ (reactions 1 and 2, Scheme 1). Although not shown in Figure 3, panel b, the SEI formed from EC/DEC/FEC after initial lithiation was the only sample we observed with appreciable $\mathrm{LiO}_{x}$ species $(0.01 \%$ of the atoms probed, Figure S2). Of the organic species present from the reduction of EC/DEC/FEC electrolyte, there was less aliphatic carbon as well as more alkoxy and carboxyl compounds compared to the EC/DEC electrolyte SEI. This is consistent with what would be expected from reaction 2 if the computationally predicted FEC reduction preferentially occurred over the EC reduction. Additionally, recent work by Martinez de la $\mathrm{Hoz}$ et al. ${ }^{60}$ has suggested that salt decomposition products such as the $\mathrm{P}_{x} \mathrm{O}_{y} \mathrm{~F}_{z}$ species, $\mathrm{LiF}$, and $\mathrm{LiOx}$ all result from multiple step reduction reactions. Significant among these findings is that phosphorus species form very stable oxide and $\mathrm{P}-\mathrm{Si}$ species on the surface of the active material. In addition to $\mathrm{PO}^{-}$ions having a high TOFSIMS cross-section, the detection of these species close to the surface in the delithiated electrodes (Figure $4 c-f$ ) is in line with these predictions.

With regards to the structure of the SEI, TOF-SIMS depth profiles (Figure 4a,b) show that after the initial lithiation, EC/ DEC/FEC produced a thicker SEI $(35.1 \mathrm{~nm})$ compared to the SEI formed in EC/DEC (23.1 nm). Additionally, EC/DEC/ FEC produced a thicker stratum of $\mathrm{LiF}$. In these electrodes, taking the stratum of SEI containing $\mathrm{LiF}$ to be where $\mathrm{LiF}_{2}{ }^{-}$ signal was greater than $50 \%$ of its maximum intensity, this layer was $\sim 4 \mathrm{~nm}$ in the SEI derived from EC/DEC (Figure $4 \mathrm{a}$ ) versus $\sim 7 \mathrm{~nm}$ (Figure $4 \mathrm{~b}$ ) from EC/DEC/FEC. The SEI structure was substantially similar in terms of the ordering of each marker species' maximum intensity for both electrolytes. Both SEI had overlapping inorganic $\left(\mathrm{PO}^{-}, \mathrm{LiF}_{2}^{-}\right)$and organic $\left(\mathrm{C}_{2} \mathrm{H}^{-}\right)$mass fragment signals far from the electrodes surface ( $50 \%$ of maximum of the $\mathrm{Si}^{-}$) with lithium oxide/hydroxide and $\mathrm{Li}_{x} \mathrm{SiO}_{y}$ close to the to the electrodes' surfaces.

The SEI that resulted from both EC/DEC and EC/DEC/ FEC evolved significantly during delithiation. XPS showed that more inorganic species and more $\mathrm{LiF}$ specifically remained after delithation for the EC/DEC/FEC SEI (Figure 3c,d). This suggests that the reactions in EC/DEC/FEC that formed the SEI during lithiation were more inorganic, irreversible, and stable. From the TOF-SIMS depth profiles (Figure 4c,d), we observe that the SEI resulting from both electrolyte systems were of similar thicknesses: $6.6 \mathrm{~nm}$ for EC/DEC and $6.1 \mathrm{~nm}$ for EC/DEC/FEC. This information, combined with the known higher concentration of $\mathrm{LiF}$ in the outer $\sim 10 \mathrm{~nm}$ of the SEI, further suggests that there is a more dense layer of $\mathrm{LiF}$ formed on the surface of the electrode cycled in EC/DEC/FEC.

There are, however, two structural differences: (1) SEI formed from EC/DEC had a thicker organic stratum on top of the inorganic species compared to the SEI formed from EC/ DEC/FEC; and (2) there is a thicker stratum of $\mathrm{LiO}^{-}$species in the depth profile of the electrode cycled in EC/DEC than the electrode cycled in EC/DEC/FEC. To explain (2), we examine Figure 4, panels $\mathrm{c}$ and $\mathrm{d}$, where $\mathrm{LiO}^{-}$fragments primarily result from $\mathrm{Li}_{x} \mathrm{SiO}_{y}$ species, as $\mathrm{LiO}_{x}$ species are 

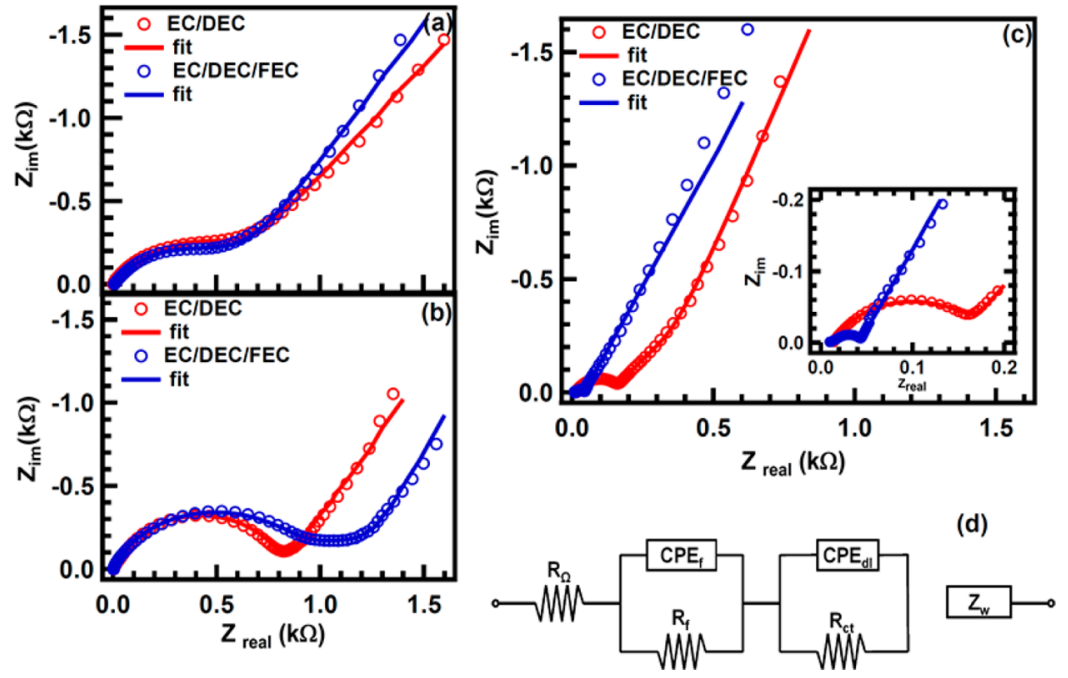

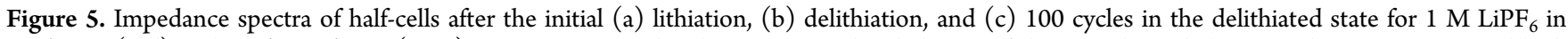
EC/DEC (red) and EC/DEC/FEC (navy). An inset in panel c shows a more detailed view of the impedance behavior at low resistances and high applied frequencies. An (d) equivalent circuit is used to model the reactions on the $a$-Si electrode varying the electrolyte. The fits for the data for each electrode are shown as solid lines.

oxidized during delithation. ${ }^{40}$ This implies that there is less $\mathrm{Li}_{x} \mathrm{SiO}_{y}$ on the electrode cycled in EC/DEC/FEC. The simplest explanation for this observation is that the FEC reduction leads to the formation of a radical organic anion and fluoride ion (similar to the reactions 1 and 2, Scheme 1) and then reacts with native oxide present on the surface, following reaction 3:

$$
\mathrm{SiO}_{\mathrm{X}}+\mathrm{xF}^{-} \rightarrow \mathrm{SiF}_{\mathrm{X}}+(\mathrm{x} / 2) \mathrm{O}_{2}
$$

This hypothesis is further supported by previous work done by Schroder et al. ${ }^{40}$ where reactive ion etched silicon produced SEI morphology and chemistry comparable to that of the SEI produced by EC/DEC/FEC after initial lithiation (Figures $3 \mathrm{~b}$ and $4 \mathrm{~b}$ ). In the following, we will further discuss the importance of this reaction with regards to SEI composition and function after 100 cycles in the delithiated state and silicon surface reactivity.

After 100 cycles, we assume the SEI to be in an approximate steady state and the differences in chemistry and structure of the SEI to be the result of the different electrolytes. The SEI produced by EC/DEC has much more carbonate and less carboxyl or oxalate species. More importantly, this electrode contains much less inorganic species, especially LiF. The TOFSIMS depth profiles (Figure 4e,f) show that EC/DEC/FEC actually produced a much thicker SEI $(72.3 \mathrm{~nm}$ compared to $20.6 \mathrm{~nm}$ ). The overall structures of both SEIs, however, are very similar in terms of the relative location of maximum signal for each of the marker species. The strata in both SEIs are arranged with $\mathrm{LiF}$ near the surface of the SEI, intermixed with organic and then $\mathrm{PO}^{-}$containing species, and then $\mathrm{LiO}^{-}$near the surface of the electrode. LiF strata thicknesses are comparable, but EC/DEC/FEC did produce a thicker layer of $11.5 \mathrm{~nm}$ versus $13.2 \mathrm{~nm}$. The layer of lithium oxide $\left(\mathrm{LiO}^{-}\right)$ species found close to the surface of each electrode produced the biggest difference in thickness between the SEI cycled in the different electrolytes. These results are very much in line with recent predictions by Balbuena and co-workers who examined computationally the effects of multiple competing reduction reactions and found $\mathrm{Li}_{2} \mathrm{O}$ and $\mathrm{P}-\mathrm{O}$ species to be important stable SEI products. ${ }^{60}$
Our results are in conflict with some of those previously reported, especially those that claim the presence of poly fluorocarbonate (poly FEC), poly(vinylene carbonate) (polyVC), and - $\mathrm{CHF}-\mathrm{OCO}_{2}$-type compunds. ${ }^{24,30,31,43}$ In some cases, it is unclear where the direct evidence for poly FEC originates in these reports. While it is possible to assign peaks in the $\mathrm{C} 1 \mathrm{~s}$ and $\mathrm{F} 1 \mathrm{~s}$ spectra to $\mathrm{C}-\mathrm{F}$ bonds, our fitting procedure was able to account for all oxidation states of carbon by the oxygen signal detected. Qualitatively, the F 1 s of the SEI produced by EC/DEC and EC/DEC/FEC in the region that would be assigned to $\mathrm{C}-\mathrm{F}$ do not look particularly different, which makes it difficult to justify why $\mathrm{C}-\mathrm{F}$ bonds should be assigned. In other cases, the detection of $\mathrm{C}-\mathrm{F}$ bonds may be due to the investigated samples having polyvinylidene fluoride (PVdF) binder, decomposed PVdF binder, or exposure to air and water. This makes it difficult to determine the origin of these species.

Schroder et al. ${ }^{39}$ have shown that limited exposure to ambient atmosphere (i.e., oxygen gas, and water vapor) dramatically changes the XPS results. We reproduce these results with SEI formed from EC/DEC/FEC that were exposed to ambient conditions in the Supporting Information (Figure S3). The literature that reports "limited" exposure does not take into account the time when a sample is loaded into an instrument during pump down when the environment around the sample is contaminating. During this time, there is continuous exposure to gaseous water vapor and oxygen until the sample antechamber reaches UHV conditions, which with off-gassing of high surface area materials may be on the order of hours. As a result, these samples are always exposed to ppm oxygen and water higher than a glovebox environment, which is a large determining factor in the irreproducibility and inaccuracy of the results. $15,39,41$

We have shown that compared to the SEI formed in the traditional electrolyte, SEI formed from EC/DEC/FEC is consistently thicker during cycling and contains more $\mathrm{LiF}$. Moreover, SEI formed from EC/DEC/FEC included different organic species after initial formation that evolved to contain much less carbonate species after 100 cycles compared to the SEI formed from EC/DEC. Additionally, the SEI from EC/ 
DEC/FEC comprised more lithium oxide and lithium fluoride species near the electrode after 100 cycles.

EIS of SEI Formed with and without FEC. To determine how the differing chemical compositions of the SEI affect its function, we carried out a series of EIS experiments. EIS is a standard analytical technique used to provide information on lithium-ion migration through surface films, charge transfer, phase transitions, and solid-state diffusion. ${ }^{24,61,62}$ In particular, we use EIS to study the resistance associated with lithium-ion migration through the SEI.

Figure 5 shows the changes in the impedance spectra of the $a-S i$ thin films in a two-electrode system after the first lithiation, first delithiation, and 100 cycles in the delithiated state. Figure 5, panel a shows Nyquist plots for electrodes cycled in EC/ DEC and EC/DEC/FEC after first lithiation. A Nyquist plot shows the real part of the measured impendence versus its imaginary component over a range of AC frequencies. To quantitatively and qualitatively analyze the impedance spectra, we turn to a model circuit of the elementary reactions that occur during electrochemical cycling (Figure 5d). The model accounts for the uncompensated ohmic resistance of an $a-S i$ electrode $\left(R_{\Omega}\right)$, the double layer capacitance of the electrode/ electrolyte interface $\left(\mathrm{CPE}_{\mathrm{f}}\right)$, resistance due to the surface reactions on the electrode $\left(R_{f}\right)$, the double-layer capacitance $\left(\mathrm{CPE}_{\mathrm{dl}}\right)$, the charge transfer resistance $\left(\mathrm{R}_{\mathrm{ct}}\right)$, and the impedance due to solid state diffusion processes, known as the Warburg impedance $\left(\mathrm{Z}_{\mathrm{w}}\right)^{24,25,63-65}$ It is widely accepted in the case of battery negative electrodes that the semicircle traces (Figure $5 \mathrm{a}-\mathrm{c})$ generated at high frequency and the associated resistance $\mathrm{R}_{\mathrm{f}}$ are due to lithium-ion migration through multilayer surface films. $^{24,62,66}$ At low frequencies, linear trends in high impedances are observed, which are attributed to the Warburg impedance $\left(\mathrm{Z}_{\mathrm{w}}\right)$ of the electrode and are due to the solid-state lithium diffusion through the $\mathrm{Li}-\mathrm{Si}$ alloy material. ${ }^{62,66,67}$

The major difference in the EIS between the electrodes cycled in EC/DEC and EC/DEC/FEC is the resistance of the surface films, $\mathrm{R}_{\mathrm{f}}$. However, since this was conducted in a two electrode cell, the impedance measurement also includes the lithium metal. The EIS data for the lithiated electrodes were fit to calculate an $R_{f}$ of $0.120 \mathrm{k} \Omega$ and $R_{c t}$ of $0.489 \mathrm{k} \Omega$ for the electrode cycled in EC/DEC/FEC, while the electrode cycled in EC/DEC had a lower $R_{f}$ of $0.067 \mathrm{k} \Omega$ and a $R_{c t}$ of $0.481 \mathrm{k} \Omega$. After the first delithiation both electrodes had an increase in impedance, the electrode cycled with EC/DEC/FEC had an $\mathrm{R}_{\mathrm{f}}$ of $0.276 \mathrm{k} \Omega$ and $\mathrm{R}_{\mathrm{ct}}$ of $0.926 \mathrm{k} \Omega$, while the electrode cycled in EC/DEC had a lower $R_{f}$ of $0.021 \mathrm{k} \Omega$ and a $R_{c t}$ of $0.785 \mathrm{k} \Omega$. The increased impedance for the electrode cycled in EC/DEC/ FEC electrolyte correlates with the work conducted by $\mathrm{Xu}$ et $\mathrm{al}^{43}$

We find that the EIS data supports the idea that the FEC produces a dense, thick, LiF-dominant SEI on the first cycle. Overall, the SEI from EC/DEC/FEC was thicker: it exhibited decreased performance in terms of overall resistance to lithium transport after initial formation. However, by compared SEI thickness to resistance in SEI produced by different methods, $\mathrm{Lu}$, Harris et al. found that thicker SEI often had more inorganics and lower resistance per unit length (depth resistivity). ${ }^{68}$ Even though the measurements came from different electrodes, we can estimate that EC/DEC/FEC produced an SEI on the order of $29.5 \Omega / \mathrm{nm}$ versus $35.5 \Omega$ / $\mathrm{nm}$ for EC/DEC.

EIS had previously been carried out on electrodes cycled for 30 and 100 cycles. $^{24,25}$ Both studies suggested that the impedance of the SEI derived from EC/DEC/FEC had lower surface film resistance. After 100 cycles, we found EC/DEC/ FEC produced an $\mathrm{R}_{\mathrm{f}}$ of $0.012 \mathrm{k} \Omega$ and a $\mathrm{R}_{\mathrm{ct}}$ of $0.021 \mathrm{k} \Omega$, while EC/DEC produced an $R_{f}$ of $0.121 \mathrm{k} \Omega$ and a $R_{c t}$ of $0.148 \mathrm{k} \Omega$, consistent with these results. As we note above, a thicker, more inorganic SEI may be more conductive per unit thickness. This helps explain how EC/DEC/FEC produced a thicker SEI on the electrode after 100 cycles (in the delithiated state), nevertheless its $R_{f}$ was smaller, and the electrode showed well-defined plateaus in the charge/discharge curves (Figure 1c).

Role of Surface Reactions in SEI Formed in EC/DEC/ FEC Compared to EC/DEC. So far, we have shown that the addition of FEC to EC/DEC (a) produces a thicker SEI; (b) changes the outer SEI chemistry to higher LiF concentration, lower aliphatic carbon initially, and less carbonate after 100 cycles; (c) changes the chemistry of the SEI closer to the electrode surface by forming $\mathrm{Li}_{2} \mathrm{O}$ and/or $\mathrm{LiOH}$ species; and (d) increases the Li-ion conductivity of the SEI after 100 cycles. These results suggest that FEC affects the SEI formation reactions in two ways: (1) $\mathrm{SiO}_{x}$ native suboxide is etched, and (2) $\mathrm{LiF}$ is produced via a facile and direct electrochemical pathway. The increased production of $\mathrm{LiF}$ is well established, but why $\mathrm{LiF}$ improves performance is not well understood. We address this topic by first tackling the contention that an etching reaction improves silicon reactivity and decreases capacity fade.

First, FEC reduces to form fluoride anions near the surface of the electrode, but previous work has failed to consider surfaces with native oxides. It is well-known that $\mathrm{F}^{-}$reacts with $\mathrm{SiO}_{x}$ suboxides, and we suggest that $\mathrm{F}^{-}$generated near the electrode is very likely to react with species other than lithium. By looking at Figure 4, panels $\mathrm{c}$ and $\mathrm{d}$, the $\mathrm{LiO}^{-}$signal from $\mathrm{SiO}_{x}$ and $\mathrm{Li}_{y} \mathrm{SiO}_{x}$ species indicates a thicker oxide layer on the interface cycled in EC/DEC than the electrode cycled in EC/DEC/FEC (previously discussed). These data are consistent with the data shown by Nakai et al. ${ }^{31}$ However, they suggest that an electrolyte not containing FEC somehow oxidized the silicon surface without suggesting a mechanism or providing supporting evidence for their conclusion. We propose that fluoride ion etching is a more likely and is a simpler explanation. Moreover, there is no reason to infer, a priori, that oxidation of the surface takes place under reducing conditions (lithiation).

Previous work has suggested that $\mathrm{Li}_{y} \mathrm{SiO}_{x}$ is a very compact and kinetically stable protective coating of the electrode; however, it is also electronically and ionically insulating. As a result, etching the surface should improve $a$-Si conductivity. ${ }^{40,52,53,55}$ Intentional removal of silicon oxide on model wafer electrodes in previous work led to formation of a thick $\mathrm{Li}_{2} \mathrm{O}$ layer, consistent with the kinetic stability model of SEI structure. ${ }^{17,40}$ The increased $\mathrm{LiO}^{-}$in TOF-SIMS depth profiles of the electrodes cycled in EC/DEC/FEC after initial lithiation (Figure 4b) and after 100 cycles (Figure 4d) further support the hypothesis that etching reaction 3 takes place.

The removal of $\mathrm{Li}_{y} \mathrm{SiO}_{x}$ may also lower interfacial resistance, which helps explain the SEI resistance observed in the EIS after 100 cycles. Additionally, the lack of $\mathrm{Li}_{y} \mathrm{SiO}_{x}$ reduces the irreversible lithium sequestration associated with this oxide layer and explains some of the increased $\mathrm{CE}$ that results from EC/DEC/FEC electrolyte.

The formation of $\mathrm{LiF}$ at the electrode surface is also important in understanding the transport properties of the SEI, 
the passivation of the surface, and the SEI evolution. As we have discussed, the elevated concentration of $\mathrm{LiF}$ in the SEI (Figure $3 \mathrm{~b}$ ) results from the direct, fast, electrochemical reduction of FEC is the evidence for the occurrence of reactions 1 and 2 (Scheme 1 ). In contrast, the electrodes cycled in EC/DEC have only an indirect path to $\mathrm{LiF}$ formation through thermal decomposition reaction $4:^{69-71}$

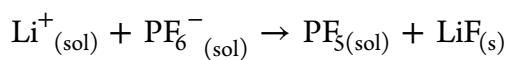

In addition, the solubility of $\mathrm{LiF}$ in liquid carbonates is very low, ${ }^{72-74}$ so the formation of $\mathrm{LiF}$ is self-perpetuating and drives further precipitation reaction 5 :

$$
\mathrm{Li}_{(\text {sol })}^{+}+\mathrm{F}_{(\text {sol })}^{-} \rightarrow \mathrm{LiF}_{(\mathrm{s})}
$$

For EC/DEC, the formation of $\mathrm{LiF}$ is reliant on the resistance at the interface of the electrode to drive the thermal decomposition of $\mathrm{LiPF}_{6}$. As a result, $\mathrm{LiF}$ formation in $\mathrm{EC} / \mathrm{DEC}$ is preceded to some extent by decomposition of the solvent into organic species to form electronically or ionically insulating species. In EC/DEC/FEC, $\mathrm{LiF}$ formation occurs by electroreduction concurrently with formation of the organic SEI species. $\mathrm{LiF}$ is known to be a more kinetically stable product under reduction compared to organic SEI products, so LiF may remain stable close to the electrode surface. ${ }^{17,75}$ Therefore, the SEI resulting from EC/DEC/FEC has a more direct path to forming kinetically stable species than $\mathrm{EC} / \mathrm{DEC}$; as a result, there is less evolution of the SEI (and improved CE) with additional cycling.

The reduction of FEC to form fluoride ions has a big impact on the desolvation of lithium ions and the transport of lithium through the SEI. Through the common ion effect, saturated solutions of $\mathrm{LiF}$ lower the free-energy barrier to desolvate (precipitate) other lithium-containing species. As a consequence, the solubility $\left(\mathrm{S}_{\mathrm{Li2}} \mathrm{O}\right)$ of $\mathrm{Li}_{2} \mathrm{O}$ decreases with lithium fluoride concentration in solution, following eq 1 :

$$
S_{\mathrm{Li}_{2} \mathrm{O}}=\sqrt[3]{\frac{\mathrm{K}_{\mathrm{SP}}}{4}}=\sqrt[3]{\frac{[\mathrm{O}]\left([\mathrm{Li}]_{\mathrm{Li}_{2} \mathrm{O}}+[\mathrm{Li}]_{\mathrm{LiF}}\right)^{2}}{4}}
$$

In this way, $\mathrm{LiF}$ formation is also coupled to $\mathrm{Li}_{2} \mathrm{O}$.

The formation of lithium oxide or hydroxide species on the surface of the electrode is important for two reasons. First, we propose that it improves Li-ion transport though the SEI. Second, the formation of the species has been shown to be quasireversible and therefore sequesters lithium to a lesser degree than other SEI species.

Schroder et al. $^{40}$ have already shown that lithium oxide species formation is quasireversible via oxidation reactions that take place when $a$-Si electrodes were delithiated (Figure $4 d$ ). The formation of the lithium oxide is due to electrolyte decomposition, ${ }^{40}$ which is detrimental to the long-term life of the cell; however, the quasireversibility of the reaction helps to explain why the electrode cycled in EC/DEC/FEC has less lithium sequestration (and thus higher $\mathrm{CE}$ ). It is difficult to gauge the importance of this degradation mechanism because results related to silicon electrodes that experience catastrophic failure after long-term cycling are rarely published (because this is a negative result). Furthermore, these results are often attributed de facto to mechanical failure of the active material or binder in composite electrodes. ${ }^{76}$ However, the degradation of the electrolyte due to continued reduction into lithium oxide might also explain this behavior.

\section{CONCLUSIONS}

Using amorphous silicon thin film model systems and anoxic, anhydrous surface analysis techniques, we have investigated the effect of FEC cosolvent in promoting a stable SEI formation. Galvanostatic cycling of the $a-S i$ thin film electrodes in electrolytes with and without FEC and $1 \mathrm{M} \mathrm{LiPF}_{6}$ salt resulted in significant difference in the $\mathrm{CE}$, consistent with prior work. It was demonstrated that cycling the electrodes in the EC/DEC/ FEC electrolyte lowered $\mathrm{CE}$ on the first cycle; however, every cycle after showed better capacity retention and CE.

The SEI that resulted from both of these electrolytes was characterized by anoxic and anhydrous XPS and TOF-SIMS. XPS showed that FEC lead to an SEI with increased concentrations of inorganic species, specifically LiF. Moreover, the organic species present in the SEI contained less aliphatic carbon in comparison to the composition of the traditional electrolyte SEI. These results are consistent with calculations conducted by Balbuena and co-workers, which suggest a kinetically fast formation of neutral radical carbonate and fluoride via a ring-opening mechanism leading to the rapid formation of LiF. The TOF-SIMS depth showed that the SEI was thicker in the electrode cycled with FEC-containing electrolyte.

Both the XPS and TOF-SIMS depth profiles showed evidence of fast reduction kinetics of FEC. Subsequent formation of $\mathrm{F}^{-}$affected the electrodes: (1) improving silicon's conductivity via silicon native oxide etching, (2) changing the solubility of lithium, which led to (3) quasireversible lithium sequestration and (4) improved Li-ion transport through the SEI via a shuttling mechanism. The style of analysis presented in this work can be further applied to understanding how SEI formation changes with other additives and on surface coatings.

With regards to SEI Li-ion transport, it has been suggested that inorganic species have preferable properties compared to organic species. One justification of this idea is that inorganic SEI species tend to have Li-ions bound in ionic bonds that facilitate hopping-type transport mechanisms. High concentrations of $\mathrm{LiF}$ relative to organic species have already been shown, in simulation, to promote rapid Li transport by Jorn et al. $^{77}$

We propose that $\mathrm{Li}_{2} \mathrm{O}$ has improved transport properties over organic species because of its ionic nature. This hypothesis is consistent with the ideas put forth by Jorn et al. and would explain the improved transport properties observed by EIS in Figure 5, panel c. Moreover, the oxidative instability of $\mathrm{Li}_{2} \mathrm{O}$ leads to desolvated lithium near the electrode's surface. This desolvated lithium, combined with the low solubility of lithium in and near the SEI, leads to an abundance of free lithium. These conditions facilitate a shuttle mechanism, decoupling the process whereby lithium leaves the electrolyte and enters the electrode, improving lithiation kinetics.

\section{ASSOCIATED CONTENT}

\section{S Supporting Information}

The Supporting Information is available free of charge on the ACS Publications website at DOI: 10.1021/acs.chemmater.5b01627.

Differential capacity plots, X-ray photoelectron spectra and fits, chemical analysis by XPS of control experiments, and scanning electron micrographs and related discussions (PDF) 


\section{AUTHOR INFORMATION}

\section{Corresponding Authors}

*E-mail: stevenson@cm.utexas.edu.

*E-mail: lwebb@cm.utexas.edu.

*E-mail: shmeng@ucsd.edu.

\section{Present Address}

${ }^{\perp}$ Chemical and Materials System Lab, General Motors Global R\&D, Warren, MI 48090, United States.

\section{Author Contributions}

${ }^{\mathrm{II}}$ These authors contributed equally. The manuscript was written through contributions of all authors. All authors have given approval to the final version of the manuscript.

\section{Funding}

This material is based on work supported as part of the program "Understanding Charge Separation and Transfer at Interfaces in Energy Materials (EFRC:CST)”, an Energy Frontier Research Center funded by the U.S. Department of Energy, Office of Science, Office of Basic Energy Sciences under Award No. DE-SC0001091. Y.S.M. and J.A. would like to acknowledge the support from the Assistant Secretary for Energy Efficiency and Renewable Energy, Office of Vehicle Technologies, U.S. Department of Energy under Contract No. DE-AC02-05CH11231, Subcontract No. 7073923 under the Advanced Battery Materials Research (BMR) Program and a California Institute for Energy and Environment (CIEE) Subaward No. PODR05-S16 from the Multiple Campus Award program of the California Energy Commission.

\section{Notes}

The authors declare no competing financial interest.

\section{ACKNOWLEDGMENTS}

K.W.S. and J.A. would like to thank Dr. Andre Dolocan, Dr. Hugo Celio, and Dr. Anthony Dylla for their thoughtful discussions concerning these experiments and their results.

\section{REFERENCES}

(1) Mukhopadhyay, A.; Sheldon, B. W. Deformation and Stress in Electrode Materials for Li-Ion Batteries. Prog. Mater. Sci. 2014, 63, 58116.

(2) Philippe, B.; Dedryvère, R.; Gorgoi, M.; Rensmo, H.; Gonbeau, D.; Edström, K. Role of the LiPF6 Salt for the Long-Term Stability of Silicon Electrodes in Li-Ion Batteries - A Photoelectron Spectroscopy Study. Chem. Mater. 2013, 25, 394.

(3) Chan, C. K.; Peng, H.; Liu, G.; Mcllwrath, K.; Zhang, X. F.; Huggins, R. A.; Cui, Y. High-Performance Lithium Battery Anodes Using Silicon Nanowires. Nat. Nanotechnol. 2008, 3, 31-35.

(4) Kim, H.; Han, B.; Choo, J.; Cho, J. Three-Dimensional Porous Silicon Particles for Use in High-Performance Lithium Secondary Batteries. Angew. Chem. 2008, 120, 10305-10308.

(5) Liu, N.; Wu, H.; McDowell, M. T.; Yao, Y.; Wang, C.; Cui, Y. A Yolk-Shell Design for Stabilized and Scalable Li-Ion Battery Alloy Anodes. Nano Lett. 2012, 12, 3315-3321.

(6) Yao, Y.; McDowell, M. T.; Ryu, I.; Wu, H.; Liu, N.; Hu, L.; Nix, W. D.; Cui, Y. Interconnected Silicon Hollow Nanospheres for Lithium-Ion Battery Anodes with Long Cycle Life. Nano Lett. 2011, 11, 2949-2954.

(7) Magasinski, A.; Dixon, P.; Hertzberg, B.; Kvit, A.; Ayala, J.; Yushin, G. High-Performance Lithium-Ion Anodes Using a Hierarchical Bottom-up Approach. Nat. Mater. 2010, 9, 353-358.

(8) Liu, X. H.; Zhong, L.; Huang, S.; Mao, S. X.; Zhu, T.; Huang, J. Y. Size-Dependent Fracture of Silicon Nanoparticles during Lithiation. ACS Nano 2012, 6, 1522-1531.

(9) Xiao, X.; Liu, P.; Verbrugge, M. W.; Haftbaradaran, H.; Gao, H. Improved Cycling Stability of Silicon Thin Film Electrodes through
Patterning for High Energy Density Lithium Batteries. J. Power Sources 2011, 196, 1409-1416.

(10) Liu, X. H.; Zhong, L.; Huang, S.; Mao, S. X.; Zhu, T.; Huang, J. Y. ACS Nano 2012, 6, 1522-1531.

(11) Su, X.; Wu, Q.; Li, J.; Xiao, X.; Lott, A.; Lu, W.; Sheldon, B. W.; $\mathrm{Wu}, \mathrm{J}$. Silicon-Based Nanomaterials for Lithium-Ion Batteries: A Review. Adv. Energy Mater. 2014, 4, n/a DOI: 10.1002/ aenm.201300882.

(12) Liu, G.; Xun, S.; Vukmirovic, N.; Song, X.; Olalde-Velasco, P.; Zheng, H.; Battaglia, V. S.; Wang, L.; Yang, W. Polymers with Tailored Electronic Structure for High Capacity Lithium Battery Electrodes. Adv. Mater. 2011, 23, 4679-4683.

(13) Piper, D. M.; Travis, J. J.; Young, M.; Son, S.-B.; Kim, S. C.; Oh, K. H.; George, S. M.; Ban, C.; Lee, S.-H. Reversible High-Capacity Si Nanocomposite Anodes for Lithium-Ion Batteries Enabled by Molecular Layer Deposition. Adv. Mater. 2014, 26, 1596-1601.

(14) Harris, S. J.; Lu, P. Effects of Inhomogeneities-Nanoscale to Mesoscale- on the Durability of Li-Ion Batteries. J. Phys. Chem. C 2013, 117, 6481-6492.

(15) Verma, P.; Maire, P.; Novák, P. A Review of the Features and Analyses of the Solid Electrolyte Interphase in Li-Ion Batteries. Electrochim. Acta 2010, 55, 6332-6341.

(16) Balbuena, P. B. In Proceedings of the 1st International Freiberg Conference on Electrochemical Storage Materials, 2014; Vol. 82, pp 8297.

(17) Peled, E.; Golodnitsky, D. In Lithium-Ion Batteries: SolidElectrolyte Interphase; Balbuena, P. B., Wang, Y., Eds.; World Scientific Publishing Company: Hackensack, NJ, 2004.

(18) Peled, E.; Ardel, G.; Golodnitsky, D. Advanced Model for Solid Electrolyte Interphase Electrodes in Liquid and Polymer Electrolytes. J. Electrochem. Soc. 1997, 144, L208-L210.

(19) Aurbach, D. In Advances in Lithium-Ion Batteries; Schalkwijk, W. A., Scrosati, B., Eds.; Kluwer Academic Publishers: Boston, MA, 2002.

(20) Deshpande, R.; Verbrugge, M. W.; Cheng, Y.-T.; Wang, J.; Liu, P. Battery Cycle Life Prediction with Coupled Chemical Degradation and Fatigue Mechanics. J. Electrochem. Soc. 2012, 159, A1730-A1738.

(21) Christensen, J.; Newman, J. A Mathematical Model for the Lithium-Ion Negative Electrode Solid Electrolyte Interphase. J. Electrochem. Soc. 2004, 151, A1977.

(22) Christensen, J.; Newman, J. Cyclable Lithium and Capacity Loss in Li-Ion Cells. J. Electrochem. Soc. 2005, 152, A818.

(23) Markevich, E.; Salitra, G.; Fridman, K.; Sharabi, R.; Gershinsky, G.; Garsuch, A.; Semrau, G.; Schmidt, M. A.; Aurbach, D. Fluoroethylene Carbonate as an Important Component in Electrolyte Solutions for High-Voltage Lithium Batteries: Role of Surface Chemistry on the Cathode. Langmuir 2014, 30, 7414-7424.

(24) Etacheri, V.; Haik, O.; Goffer, Y.; Roberts, G. a.; Stefan, I. C.; Fasching, R; Aurbach, D. Effect of Fluoroethylene Carbonate (FEC) on the Performance and Surface Chemistry of Si-Nanowire Li-Ion Battery Anodes. Langmuir 2012, 28, 965-976.

(25) Lin, Y.-M.; Klavetter, K. C.; Abel, P. R.; Davy, N. C.; Snider, J. L.; Heller, A.; Mullins, C. B. High Performance Silicon Nanoparticle Anode in Fluoroethylene Carbonate-Based Electrolyte for Li-Ion Batteries. Chem. Commun. 2012, 48, 7268-7270.

(26) Chockla, A. M.; Klavetter, K. C.; Mullins, C. B.; Korgel, B. A. Solution-Grown Germanium Nanowire Anodes for Lithium-Ion Batteries. ACS Appl. Mater. Interfaces 2012, 4, 4658-4664.

(27) Martínez de la Hoz, J. M.; Balbuena, P. B. Reduction Mechanisms of Additives on Si Anodes of Li-Ion Batteries. Phys. Chem. Chem. Phys. 2014, 16, 17091-17098.

(28) Leung, K.; Rempe, S. B.; Foster, M. E.; Ma, Y.; Martinez del la Hoz, J. M.; Sai, N.; Balbuena, P. B. Modeling Electrochemical Decomposition of Fluoroethylene Carbonate on Silicon Anode Surfaces in Lithium Ion Batteries. J. Electrochem. Soc. 2013, 161, A213-A221.

(29) Ma, Y.; Balbuena, P. B. DFT Study of Reduction Mechanisms of Ethylene Carbonate and Fluoroethylene Carbonate on Li+-Adsorbed Si Clusters. J. Electrochem. Soc. 2014, 161, E3097-E3109. 
(30) Nguyen, C. C.; Lucht, B. L. Comparative Study of Fluoroethylene Carbonate and Vinylene Carbonate for Silicon Anodes in Lithium Ion Batteries. J. Electrochem. Soc. 2014, 161, A1933-A1938.

(31) Nakai, H.; Kubota, T.; Kita, A.; Kawashima, A. Investigation of the Solid Electrolyte Interphase Formed by Fluoroethylene Carbonate on Si Electrodes. J. Electrochem. Soc. 2011, 158, A798-A801.

(32) Xiao, A.; Yang, L.; Lucht, B. L.; Kang, S.-H.; Abraham, D. P. Examining the Solid Electrolyte Interphase on Binder-Free Graphite Electrodes. J. Electrochem. Soc. 2009, 156, A318.

(33) Kang, S.-H.; Abraham, D. P.; Xiao, A.; Lucht, B. L. Investigating the Solid Electrolyte Interphase Using Binder-Free Graphite Electrodes. J. Power Sources 2008, 175, 526-532.

(34) Nie, M.; Chalasani, D.; Abraham, D. P.; Chen, Y.; Bose, A.j Lucht, B. L. Lithium Ion Battery Graphite Solid Electrolyte Interphase Revealed by Microscopy and Spectroscopy. J. Phys. Chem. C 2013, 117, 1257-1267.

(35) Nie, M.; Abraham, D. P.; Chen, Y.; Bose, A.; Lucht, B. L. Silicon Solid Electrolyte Interphase (SEI) of Lithium Ion Battery Characterized by Microscopy and Spectroscopy. J. Phys. Chem. C 2013, 117, 13403-13412.

(36) Li, J.; Dozier, A. K.; Li, Y.; Yang, F.; Cheng, Y.-T. Crack Pattern Formation in Thin Film Lithium-Ion Battery Electrodes. J. Electrochem. Soc. 2011, 158, A689-A694.

(37) Wang, J. W.; He, Y.; Fan, F.; Liu, X. H.; Xia, S.; Liu, Y.; Harris, C. T.; Li, H.; Huang, J. Y.; Mao, S. X.; Zhu, T. Two-Phase Electrochemical Lithiation in Amorphous Silicon. Nano Lett. 2013, 13, 709-715.

(38) Liu, X. H.; Wang, J. W.; Huang, S.; Fan, F.; Huang, X.; Liu, Y.; Krylyuk, S.; Yoo, J.; Dayeh, S. A.; Davydov, A. V.; et al. In Situ AtomicScale Imaging of Electrochemical Lithiation in Silicon. Nat. Nanotechnol. 2012, 7, 749-756.

(39) Schroder, K. W.; Celio, H.; Webb, L. J.; Stevenson, K. J. Examining Solid Electrolyte Interphase Formation on Crystalline Silicon Electrodes: Influence of Electrochemical Preparation and Ambient Exposure Conditions. J. Phys. Chem. C 2012, 116, 1973719747.

(40) Schroder, K. W.; Dylla, A. G.; Harris, S. J.; Webb, L. J.; Stevenson, K. J. Role of Surface Oxides in the Formation of SolidElectrolyte Interphases at Silicon Electrodes for Lithium-Ion Batteries. ACS Appl. Mater. Interfaces 2014, 6, 21510-21524.

(41) Malmgren, S.; Ciosek, K.; Lindblad, R.; Plogmaker, S.; Kühn, J.; Rensmo, H.; Edström, K.; Hahlin, M. Consequences of Air Exposure on the Lithiated Graphite SEI. Electrochim. Acta 2013, 105, 83-91.

(42) Pereira-Nabais, C.; Światowska, J.; Rosso, M.; Ozanam, F.; Seyeux, A.; Gohier, A.; Tran-Van, P.; Cassir, M.; Marcus, P. Effect of Lithiation Potential and Cycling on Chemical and Morphological Evolution of Si Thin Film Electrode Studied by ToF-SIMS. ACS Appl. Mater. Interfaces 2014, 6, 13023-13033.

(43) Xu, C.; Lindgren, F.; Philippe, B.; Gorgoi, M.; Björefors, F.; Edstrom, K.; Gustafsson, T.; Xu, C.; Lindgren, F.; Philippe, B.; Gorgoi, M.; Björefors, F. Improved Performance of Silicon Anode for Li-Ion Batteries: Understanding the Surface Modification Mechanism of Fluoroethylene Carbonate as an Effective Electrolyte Additive Improved Performance of Silicon Anode for Li-Ion Batteries: Understanding the Surface Modification Mechanism of Fluoroethylene Carbonate as an Effective Electrolyte Additive. Chem. Mater. 2015, 27, 2591.

(44) Celio, H.; et al. Interface Designed with Differential Pumping and Built-in Figure of Merit Method to Monitor Chambers where Environmentally Sensitive Samples are Prepared and Transferred for Analysis. U.S. Patent Appl. 14/445,650, 2014.

(45) Green, F. M.; Gilmore, I. S.; Seah, M. P. TOF-SIMS: Accurate Mass Scale Calibration. J. Am. Soc. Mass Spectrom. 2006, 17, 514-523.

(46) Elko-Hansen, T. D.-M.; Dolocan, A.; Ekerdt, J. G. Atomic Interdiffusion and Diffusive Stabilization of Cobalt by Copper During Atomic Layer Deposition from Bis(N-Tert-Butyl-N'-Ethylpropionamidinato) Cobalt(II). J. Phys. Chem. Lett. 2014, 5, 1091-9.

(47) Zimmerman, J. D.; Lassiter, B. E.; Xiao, X.; Sun, K.; Dolocan, A.; Gearba, R.; Vanden Bout, D. A.; Stevenson, K. J.; Wickramasinghe, P.;
Thompson, M. E.; Forrest, S. R. Control of Interface Order by Inverse Quasi-Epitaxial Growth of Squaraine/fullerene Thin Film Photovoltaics. ACS Nano 2013, 7, 9268-9275.

(48) Perez, F.; Granger, B. E. IPython: A System for Interactive Scientific Computing. Comput. Sci. Eng. 2007, 9, 21-29.

(49) Van der Walt, S.; Colbert, S. C.; Varoquaux, G. The NumPy Array: A Structure for Efficient Numerical Computation. Comput. Sci. Eng. 2011, 13, 22-30.

(50) Jones, E.; Oliphant, T.; Peterson, P.; et al. SciPy: Open Source Scientific Tools for Python, 2015. http://www.scipy.org/.

(51) McKinney, W. Data Structures for Statistical Computing in Python. Proc. 9th Python Sci. Conf., 2010; pp 51-56.

(52) Philippe, B.; Dedryvère, R.; Allouche, J.; Lindgren, F.; Gorgoi, M.; Rensmo, H.; Gonbeau, D.; Edström, K. Nanosilicon Electrodes for Lithium-Ion Batteries: Interfacial Mechanisms Studied by Hard and Soft X-Ray Photoelectron Spectroscopy. Chem. Mater. 2012, 24, 1107-1115.

(53) Radvanyi, E.; De Vito, E.; Porcher, W.; Jouanneau Si Larbi, S. An XPS/AES Comparative Study of the Surface Behaviour of NanoSilicon Anodes for Li-Ion Batteries. J. Anal. At. Spectrom. 2014, 29, $1120-1131$

(54) Martin, L.; Martinez, H.; Ulldemolins, M.; Pecquenard, B.; Le Cras, F. Evolution of the Si Electrode/electrolyte Interface in Lithium Batteries Characterized by XPS and AFM Techniques: The Influence of Vinylene Carbonate Additive. Solid State Ionics 2012, 215, 36-44.

(55) Radvanyi, E.; De Vito, E.; Porcher, W.; Danet, J.; Desbois, P.; Colin, J.-F.; Si Larbi, S. J. Study of Lithiation Mechanisms in Silicon Electrodes by Auger Electron Spectroscopy. J. Mater. Chem. A 2013, 1, 4956-4965.

(56) Memarzadeh Lotfabad, E.; Kalisvaart, P.; Kohandehghan, A.; Karpuzov, D.; Mitlin, D. Origin of Non-SEI Related Coulombic Efficiency Loss in Carbons Tested against $\mathrm{Na}$ and Li. J. Mater. Chem. A 2014, 2, 19685-19695.

(57) Peled, E.; Golodnitsky, D.; Menachem, C.; Bar-Tow, D. An Advanced Tool for the Selection of Electrolyte Components for Rechargeable Lithium Batteries. J. Electrochem. Soc. 1998, 145, 3482.

(58) Peled, E.; Golodnitsky, D.; Ardel, G.; Eshkenazy, V. The Sei Model-application to Lithium-Polymer Electrolyte Batteries. Electrochim. Acta 1995, 40, 2197-2204.

(59) Veryovkin, I. V.; Tripa, C. E.; Zinovev, a. V.; Baryshev, S. V.; Li, Y.; Abraham, D. P. TOF SIMS Characterization of SEI Layer on Battery Electrodes. Nucl. Instrum. Methods Phys. Res., Sect. B 2014, 332, 368-372.

(60) Martinez de la Hoz, J. M.; Soto, F. a.; Balbuena, P. B. Effect of the Electrolyte Composition on SEI Reactions at Si Anodes of Li-Ion Batteries. J. Phys. Chem. C 2015, 119, 7060-7068.

(61) Chen, L.; Wang, K.; Xie, X.; Xie, J. Effect of Vinylene Carbonate (VC) as Electrolyte Additive on Electrochemical Performance of $\mathrm{Si}$ Film Anode for Lithium Ion Batteries. J. Power Sources 2007, 174, $538-543$.

(62) Cho, H.-M.; Meng, Y. S. Effect of Ni/Mn Ordering on Elementary Polarizations of LiNi0.5Mn1.5O4 Spinel and Its Nanostructured Electrode. J. Electrochem. Soc. 2013, 160, A1482-A1488.

(63) Chan, C. K.; Ruffo, R.; Hong, S. S.; Cui, Y. Surface Chemistry and Morphology of the Solid Electrolyte Interphase on Silicon Nanowire Lithium-Ion Battery Anodes. J. Power Sources 2009, 189, $1132-1140$.

(64) Wang, M. S.; Fan, L. Z. Silicon/carbon Nanocomposite Pyrolyzed from Phenolic Resin as Anode Materials for Lithium-Ion Batteries. J. Power Sources 2013, 244, 570-574.

(65) Xiao, Y.; Hao, D.; Chen, H.; Gong, Z.; Yang, Y. Economical Synthesis and Promotion of the Electrochemical Performance of Silicon Nanowires as Anode Material in Li-Ion Batteries. ACS Appl. Mater. Interfaces 2013, 5, 1681-1687.

(66) Aurbach, D.; Markovsky, B.; Weissman, I.; Levi, E.; Ein-Eli, Y. On the Correlation between Surface Chemistry and Performance of Graphite Negative Electrodes for Li Ion Batteries. Electrochim. Acta 1999, 45, 67-86. 
(67) Pyun, S.-I.; Bae, J.-S. The Ac Impedance Study of Electrochemical Lithium Intercalation into Porous Vanadium Oxide Electrode. Electrochim. Acta 1996, 41, 919-925.

(68) Lu, P.; Li, C.; Schneider, E. W.; Harris, S. J. Chemistry, Impedance, and Morphology Evolution in Solid Electrolyte Interphase Films during Formation in Lithium Ion Batteries. J. Phys. Chem. C 2014, 118, 896-903.

(69) Wang, Q.; Sun, J.; Yao, X.; Chen, C. Thermal Stability of LiPF 6 / EC+DEC Electrolyte with Charged Electrodes for Lithium Ion Batteries. Thermochim. Acta 2005, 437, 12-16.

(70) Zinigrad, E.; Larush-Asraf, L.; Gnanaraj, J. S.; Sprecher, M.; Aurbach, D. On the Thermal Stability of $\mathrm{LiPF}_{6}$. Thermochim. Acta 2005, 438, 184-191.

(71) Yang, H.; Zhuang, G. V.; Ross, P. N. Thermal Stability of LiPF6 Salt and Li-Ion Battery Electrolytes Containing LiPF6. J. Power Sources 2006, 161, 573-579.

(72) Jones, J.; Anouti, M.; Caillon-Caravanier, M.; Willmann, P.; Lemordant, D. Lithium Fluoride Dissolution Equilibria in Cyclic Alkylcarbonates and Water. J. Mol. Liq. 2010, 153, 146-152.

(73) Tasaki, K.; Harris, S. J. Computational Study on the Solubility of Lithium Salts Formed on Lithium Ion Battery Negative Electrode in Organic Solvents. J. Phys. Chem. C 2010, 114, 8076-8083.

(74) Tasaki, K.; Goldberg, A.; Lian, J.-J.; Walker, M.; Timmons, A. T.; Harris, S. J. Solubility of Lithium Salts Formed on the Lithium-Ion Battery Negative Electrode Surface in Organic Solvents. J. Electrochem. Soc. 2009, 156, A1019.

(75) Peled, E.; Golodnttsky, D.; Ardel, G.; Menachem, C.; Bar Tow, D.; Eshkenazy, V. MRS Online Proc. Libr. 1995, 393, 209.

(76) Bogart, T. D.; Chockla, A. M.; Korgel, B. a. High Capacity Lithium Ion Battery Anodes of Silicon and Germanium. Curr. Opin. Chem. Eng. 2013, 2, 286-293.

(77) Jorn, R.; Kumar, R.; Abraham, D. P.; Voth, G. a. Atomistic Modeling of the Electrode-Electrolyte Interface in Li-Ion Energy Storage Systems: Electrolyte Structuring. J. Phys. Chem. C 2013, 117, $3747-3761$. 